\title{
Locker-Room Experiences Among LGBTQ+ Adults
}

\author{
Shannon S.C. Herrick and Lindsay R. Duncan \\ McGill University
}

\begin{abstract}
Locker rooms operate as pivotal access points to physical activity across sports, physical education, and fitness facilities. However, locker rooms are predicated on cis-heterosexual assumptions that can be isolating to LGBTQ+ individuals. Using an online cross-sectional survey, LGBTQ+ adults $(N=1,067)$ were asked open-response questions about their past and present locker-room experiences. The resulting texts were independently coded by two researchers using thematic analysis and compared. All discrepancies were discussed with and rectified by a third researcher who acted as a critical peer. The results present distinct experiences across three intersecting aspects of embodiment: self-conscious-"I hate(d) being seen," sexual transgression, and gender transgression. The findings provide insight into how harmful LGBTQ+ stereotypes influence lockerroom experiences and support the redesign of locker rooms to challenge the binary organization of these spaces.
\end{abstract}

Keywords: exercise, gender, physical activity, sexuality, transgender

Physical activity takes places in a variety of settings, such as physical education, fitness facilities, and organized sports-all of which have locker rooms as critical access points (Fusco, 2006a). Locker rooms are organized according to widespread assumptions that everyone is (a) cisgender or cis, where your gender identity matches the sex you were assigned at birth and (b) heterosexual (Cover, 2003; Hekma, 1998). Typically, facilities only provide two locker rooms, strictly coded via the gender binary of men's versus women's spaces (Eckes, 2017; Sykes, 2011). The division of locker rooms is justified through heterosexual standards that presume men and women cannot share spaces of nonsexualized nudity (Fusco, 2006a, 2012; Sykes, 2011). In addition, locker rooms are governed by the implicit understanding that patrons must adhere to a variety of conventions from hygienic to behavioral standards (Fusco, 2006a). Subsequently, locker rooms have fostered a culture of surveillance whereby bodies and identities that deviate from a narrow range recognized as "normal" or "healthy" (i.e., cisgender heterosexual able-bodied, etc.) are subject to increased scrutiny from fellow patrons (Fusco, 2006b; Sykes, 2011).

LGBTQ+ is an acronym used to acknowledge lesbian, gay, bisexual, transgender, queer, and other communities that do not adhere to cis-heterosexist assumptions (Griffith et al., 2017). "Transgender" is an umbrella term that can be used to describe any number of experiences, expressions, and identities that are not classified as cisgender (Davidson, 2007). LGBTQ+ encompasses a range of identities and expressions that span across gender and sexuality. Heterosexuality simultaneously perpetuates and is predicated on the gender binary (Jackson, 2006), meaning that if you are assigned female at birth it is assumed that you will be sexually attracted to men and if you are assigned male at birth it is assumed that you will be sexually attracted to women. Operating under the prevalent assumption that heterosexuality is the "default" sexual orientation, sexuality is inherently linked with sex to the point of conflation. In contrast to the rigidity of cis-heterosexuality,

The authors are with the McGill Research Center for Physical Activity and Health, Dept. of Kinesiology and Physical Education, McGill University, Montreal, QC, Canada. Herrick (shannon.herrick@mail.mcgill.ca) is corresponding author.
LGBTQ+ lived experiences can represent a multiplicity of and fluidity between expressions of sexuality and gender.

Individuals who identify as LGBTQ+ defy these widespread cis-heterosexual assumptions and, subsequently, experience discrimination, stigmatization, and marginalization in a variety of contexts (Dermer, Smith, \& Barto, 2010; Subhrajit, 2014). One such context is physical activity, where discrimination based on sexual orientation and/or gender identity complicates or excludes participation (e.g., Denison \& Kitchen, 2015; DevísDevís, Pereira-García, López-Cañada, Pérez-Samaniego, \& Fuentes-Miguel, 2018; Fredriksen-Goldsen, Kim, Bryan, Shiu, \& Emlet, 2017; Gill, Morrow, Collins, Lucey, \& Schultz, 2010). Locker rooms, in particular, operate as spaces where limited tolerance for and rejection of suspected or openly LGBTQ+ patrons is expected (Eng, 2008; Sykes, 2011). To maintain the implicit cisheterosexuality of locker rooms, LGBTQ+ individuals are often perceived as predacious and persecuted accordingly (Eng, 2008; Pérez-Samaniego, Fuentes-Miguel, Pereira-García, López-Cañada, \& Devís-Devís, 2019). In 2017, the Gay, Lesbian, and Straight Education Network conducted their biennial National School Climate Survey to document the unique challenges faced by LGBTQ+ middle and high school students $(N=23,001)$. The findings from this study show that $40 \%$ of LGBTQ+ students across the United States avoided locker rooms because they felt uncomfortable or unsafe accessing them (Kosciw, Greytak, Zongrone, Clark, \& Truong, 2018). Overall, locker rooms are perceived as one of the most traumatic spaces for LGBTQ+ individuals and pose a significant barrier to LGBTQ+ participation in physical activity (Fusco, 2006b; Greenspan, Griffith, Hayes, \& Murtagh, 2019; Jones, Arcelus, Bouman, \& Haycraft, 2017b; Sykes, 2009).

Shifting societal conceptions of masculinity and increased acceptance of LGBTQ+ individuals in Western society are gradually influencing locker-room cultures to be more inclusive of LGBTQ+ patrons (Lewis et al., 2017; Short, 2007), most notably for lesbian and gay athletes (e.g., Magrath, Anderson, \& Roberts, 2015; Mann \& Krane, 2018). For example, interviews with 22 high-level cis-male soccer players revealed that heterosexual athletes were not concerned about sharing a locker room with a gay 
teammate (Magrath et al., 2015). Similarly, a study of cis-female intercollegiate athletes demonstrated that team sports are transitioning toward the acceptance of diverse sexual identities (Mann \& Krane, 2018). Although team sport cultures may be trending toward inclusion, locker rooms are not limited to organized sporting contexts. The qBody Project was conducted to explore the retrospective experiences of physical education through interviews with 39 adults that self-identified as having queer bodies (Sykes, 2009, 2011). Memories of locker rooms in physical education were found to be disquieting and especially traumatic for transgender individuals (Sykes, 2011). Recent studies focused on transgender experiences within physical activity have specifically problematized locker rooms for dissuading transgender participation (e.g., Devís-Devís et al., 2018; Jones, Arcelus, Bouman, \& Haycraft, 2017a). A study involving focus groups with LGBTQ+ adults $(N=42)$ also found that negative childhood memories of locker rooms influenced how LGBTQ+ adults interpreted and (dis) engaged from these spaces (Herrick \& Duncan, 2018a). Despite these findings and reports calling for more inclusive locker rooms (e.g., Beemyn, Domingue, Pettitt, \& Smith, 2005; Cunningham, Buzuvis, \& Mosier, 2018), limited progress toward LGBTQ+ inclusion has been made.

Given the breadth of lived experiences that fall under the LGBTQ+ umbrella, this study sought to represent and further understand the multiplicity and diversity of experiences LGBTQ + individuals have within locker rooms. Subsequently, this study sought to answer the following questions using qualitative responses from a large-scale sample of LGBTQ+ adults: (a) What are the experiences of self-identifying LGBTQ+ adults in locker-room spaces? and (b) How do these experiences influence overall physical activity experiences?

\section{Method}

\section{Ontological and Epistemological Considerations}

This research has been primarily conducted through the lens of the first author's experiences as a self-identified White settler queer cisfemme. The first author's research is paradigmatically situated in critical theory, wherein they subscribe to a historical realist ontology which assumes that realities are shaped by social, political, cultural, and economic values that determine which realities will be privileged within a research context (Mertens, 2007; Scotland, 2012). Within critical theory epistemology, knowledge claims are (a) socially constructed, (b) influenced by power relations, and (c) inherently political (Scotland, 2012). Their transformative research has an emancipatory purpose, with this study focused on spreading awareness of LGBTQ+ locker-room experiences and critiquing exclusionary practices embedded within locker rooms.

\section{Questionnaire Development}

This study received institutional approval from the McGill University Research Ethics Board-II and involves an analysis of qualitative written responses collected from a multicomponent survey that explored a theoretical model for understanding how stresses associated with being LGBTQ+ relate to motivation for physical activity (Herrick, Rocchi, Sweet, \& Duncan, 2019). Prior to launching the multicomponent survey, its contents were discussed in a series of four focus groups by self-identified LGBTQ+ adults $(N=22)$ who emphasized the need to incorporate openended questions. For example, Christian (a 30-year-old White queer agender individual ${ }^{1}$ ) said, "these 'rate my life on a scale of 1 to 5' questions only show part of the picture. I want-no, need spaces to really explain my experiences." Through these in-depth discussions, the participants posed, deliberated, and refined several open-ended questions that they wanted to be incorporated into the survey.

Upon the conclusion of the four focus groups, the survey was modified to include seven optional open-ended questions (see Table 1) dispersed throughout the survey to explore aspects of LGBTQ+ experiences within physical activity contexts. Within each focus group that suggested the addition of an open-ended question, the topic and the wording of the question were thoroughly discussed. All focus group participants $(N=22)$ felt strongly about the addition of one open-ended question specifically asking about their experiences with locker rooms. Subsequently, the question "How would you describe your current and/or past experiences with changing rooms or locker rooms?" was integrated into the survey.

\section{Participants}

Eligible participants (a) were 18 years or older, (b) self-identified as LGBTQ+, (c) were able to read and write in English, and (d) had access to the Internet. Data were collected about participants' age, ethnicity, highest level of education, annual household income, relationship status, sexual orientation, gender identity, gender expression, and how many years they have publicly identified as LGBTQ+. Table 2 provides an overview of the demographic information associated with our participants.

\section{Procedure}

The participants were recruited online through public posts on LGBTQ+ community groups, LGBTQ+ campus groups, and LGBTQ+ affiliated Facebook groups based in North America (Meyer \& Wilson, 2009). Interested individuals were directed to an online consent form detailing the study itself, the survey

\section{Table 1 Open-Ended Questions Included in Online Survey}

1. What does "queer" mean to you?

2. How do you think your identity as an LGBTQ+ individual has influenced and/or currently influences your experiences with physical activity?

3. Are there any accessibility issues you might face to engage in physical activity (e.g., racism, financial limitations, religious affiliations, ableism, etc.)? Please elaborate.

4. In what ways do you think physical activity could be altered to be more inclusive of LGBTQ+ participation?

5. How would you describe your past and/or current relationships with teammates, coaches, and other sport-related support staff?

6. How would you describe your current and/or past experiences with changing rooms or locker rooms?

7. How would you describe your current relationship with exercise? 
Table 2 General Demographic Variables

\begin{tabular}{|c|c|c|}
\hline Variable & $M(S D)$ & Range \\
\hline Age (years) & $29.4(9.2)$ & $18-69$ \\
\hline \multirow[t]{2}{*}{ Years publicly out } & $8.5(7.7)$ & $0-49$ \\
\hline & $n$ & $\%$ \\
\hline \multicolumn{3}{|l|}{ Gender identity } \\
\hline Ciswoman & 427 & 40.0 \\
\hline Cisman & 318 & 29.8 \\
\hline Nonbinary & 183 & 17.2 \\
\hline Transman & 88 & 8.2 \\
\hline Transwoman & 51 & 4.8 \\
\hline \multicolumn{3}{|l|}{ Sexuality } \\
\hline Queer & 289 & 27.1 \\
\hline Lesbian & 222 & 20.8 \\
\hline Gay & 168 & 15.7 \\
\hline Bisexual & 153 & 14.3 \\
\hline Pansexual & 89 & 8.3 \\
\hline Demisexual & 53 & 5.0 \\
\hline Asexual & 67 & 6.3 \\
\hline Questioning & 21 & 2.0 \\
\hline Heterosexual & 5 & 0.5 \\
\hline \multicolumn{3}{|l|}{ Ethnicity } \\
\hline White & 712 & 66.7 \\
\hline Hispanic & 67 & 6.3 \\
\hline Mixed race & 54 & 5.0 \\
\hline Indigenous & 51 & 4.8 \\
\hline South Asian & 49 & 4.6 \\
\hline African & 46 & 4.3 \\
\hline East Asian & 42 & 3.9 \\
\hline Middle Eastern & 34 & 3.2 \\
\hline Caribbean & 12 & 1.1 \\
\hline \multicolumn{3}{|l|}{ Education } \\
\hline Undergraduate/baccalaureate & 273 & 25.6 \\
\hline Some college & 211 & 19.8 \\
\hline Master's degree & 187 & 17.5 \\
\hline High school diploma/GED & 151 & 14.2 \\
\hline Some college postundergraduate & 104 & 9.7 \\
\hline Vocational/training school & 49 & 4.6 \\
\hline Doctoral degree & 38 & 3.5 \\
\hline CEGEP/DEC & 25 & 2.3 \\
\hline Some high school & 17 & 1.6 \\
\hline Did not attend high school & 7 & 0.7 \\
\hline Other & 5 & 0.5 \\
\hline \multicolumn{3}{|l|}{ Annual household income (\$) } \\
\hline$<25,000$ & 251 & 23.5 \\
\hline $25,001-50,000$ & 207 & 19.4 \\
\hline $50,001-75,000$ & 174 & 16.3 \\
\hline $75,001-100,000$ & 152 & 14.2 \\
\hline $100,001-125,000$ & 111 & 10.4 \\
\hline $125,001-150,000$ & 67 & 6.3 \\
\hline$>150,001$ & 79 & 7.4 \\
\hline Prefer not to say & 26 & 2.4 \\
\hline
\end{tabular}

Note. GED = high-school equivalency certificate; CEGEP = Collége d'enseignement général et professionnel; $\mathrm{DEC}=$ diplôme d'études collégiales. components, and their rights as participants. The participants who acknowledged that they had read the consent form and submitted their informed online consent were then redirected to the online survey. No incentive was offered to the participants. The online survey was hosted on Qualtrics, and the responses were collected for 6 months from August 2017 to January 2018.

\section{Analysis}

The data collection yielded responses about locker-room experiences from 1,067 participants, which ranged from four to over 1,000 words. Despite there being a specific question dedicated to locker rooms, the participants also discussed their experiences with locker rooms in response to other open-ended questions. Given the breadth of the responses, we opted to use inductive thematic analysis (Braun, Clarke, \& Weate, 2016; Clarke \& Braun, 2013) to code patterned meanings observed across the large number of submitted responses (Smith \& Sparkes, 2005). Before coding, the first author and a research assistant independently read all of the submitted responses twice to thoroughly familiarize themselves with the contents of the responses. Then the two coders proceeded to independently code the responses to one question at a time. The coders were in frequent contact throughout the process to discuss and ultimately ensure consensus between codes. After each question was coded, discussions were held to explore the relationships and boundaries between the themes across all previously coded questions. These discussions facilitated an iterative analysis where, despite being coded sequentially, each question and its responses were considered to be a part of a whole. The resulting candidate themes were then reviewed by the second author, who acted as a critical peer to help ensure the transparency and credibility of the results (Smith \& Caddick, 2012; Smith \& McGannon, 2018). Both authors then engaged in a collaborative discussion and came to a consensus on how the results should be presented in a way that is reflective of the data as a whole.

\section{Results}

When recalling experiences with locker rooms, the participants $(N=1,067)$ commonly referred to aspects of their own embodiment to situate and contextualize their responses. The majority of the participants expressed some level of discomfort accessing change rooms or locker rooms. Feelings of insecurity within locker rooms seemed to be related to the participants' body image, sexuality, gender expression, and gender identity. Through our data analysis, we generated three themes that detail how different aspects of embodiment influenced LGBTQ+ experiences within locker rooms: (a) self-conscious: "I hate(d) being seen," (b) sexual transgression, and (c) gender transgression. All of the responses from the participants are presented as they were submitted, meaning that the use of parentheses is a part of the responses from the participants. Any modifications made by authors (i.e., the redaction of specific places) are marked with the use of square brackets.

\section{Self-Conscious: "I Hate(d) Being Seen"}

Locker rooms operate as sites where the naked body can be subjected to the gaze of others. For some, the nudity expressed and expected within locker rooms was intimidating and complicated to navigate. Theo, a 32-year-old White pansexual genderqueer individual, explained how "when I use the changerooms at 
the gym, I feel very intimidated by all of the nudity." For some participants, these feelings of awkwardness revolving around nudity were viewed as separate from their sexuality. Eric, a 23-year-old White gay cisman, noted how "I am uncomfortable in locker rooms, not so much because I'm gay, but because I'd just rather not be naked in front of strangers." The participants also grappled with how the nudity displayed in locker rooms inherently reinforced fatphobia and other iterations of body shaming, such as thin shaming. For example, Timber (a 25-yearold mixed race bisexual cisman) explained how "I'm stick skinny, so I don't like changing publicly. People used to call me Skeletor-which doesn't even make sense because he's pretty buff, but regardless, I still feel insecure about the way my bones stick out." Fatphobia and body shaming practices, for some participants, transcended sexuality and gender as Laura, a 24year-old White asexual ciswoman, explained: "I'm always a little afraid of being judged for my body, but that's not $100 \%$ a matter of being LGBTQ+."

Negative connotations associated with being overweight or obese seemed to be exacerbated for the participants when attempting to use locker rooms, assumedly due to the expected nudity. Cynthia, a 34-year-old White bisexual ciswoman, noted that "locker rooms are terrible, but it's not because I'm bi-it's because I' $m$ fat. I feel watched and judged in those spaces. I hate(d) being seen." The participants commonly cited their current or past body image issues as the basis for their feelings of self-consciousness when using locker rooms. Kayden, a 22-year-old White bisexual nonbinary femme-centered individual with a slight mobility impairment, expressed how "I've never tried to use a locker room designated for anything other than the gender I was assigned at birth, but I've always felt shy to change in front of others because of my body image issues." Within locker rooms, symbolic associations between fat and femininity (in opposition to athleticism and masculinity) became extremely pronounced for some participants. For Mateo, a 32-year-old Hispanic queer cisman, locker rooms were interpreted as arenas for his masculinity to be scrutinized by other patrons:

I still find locker rooms intimidating and try to avoid them when I can. It feels like a space to judge one another. While I'm not overweight, I have felt that because I've been working on endurance training sports and not muscle definition (an arbitrary marker of masculinity), I'm being judged for my lack of performing as a "man."

Despite not identifying as overweight, Mateo still felt that in not striving toward muscularity he was deviating from traditional conceptions of masculinity and, therefore, was subject to judgment. Everett, a 22-year-old White queer cisman and recreational dancer, echoed these sentiments by expressing how "I have never liked locker rooms. I have always felt like the biggest guy in the room, and not in the good macho way but in the fat sissy way."

Although some participants viewed their body image as being somewhat independent from their LGBTQ+ identity, some participants did not. Adam, a 24-year-old White gay cisman, discussed how 'I'm only shy in locker rooms because of my weight—it's complicated for gay men. Well ... it's complicated if you're gay and you're muscular and hot." Many male identifying participants spoke to the challenges associated with being measured by other locker-room patrons against rigid standards of attractiveness for gay men. For example, Elijah (a 28-year-old White gay cisman) explained how "I'm skinny straight but gay fat. I have to have way higher standards for the way my body looks because I'm gay, when they're actually low for my health." Among gay male communities, great emphasis can be placed on being thin and muscular to be considered conventionally attractive. Carter (a 23-year-old Middle Eastern gay cisman) described how "I feel under a microscope in locker rooms-I' $m$ a chubby gay man of color. I'm trying to feel more confident but it's a difficult journey when gay culture says that I need to be jacked, lean, and blonde."

The participants spoke to their experiences attempting to navigate the nuanced intersection between their body image, sexuality, and gender. "I'm overweight and visibly queer," explained Yael, a 25-year-old White queer nonbinary individual. Yael continued, "locker rooms are nerve-wracking to navigate. Do I not talk to anyone? Do I hide in a stall, so I don't show my body or see others' bodies? Am I invading a space for women to be non-sexualized?" Similarly, Leah, a 31-year-old White lesbian ciswoman, explained how:

I think my body image and LGBTQ+ identity are connected. There is nothing wrong with being a gay overweight woman. It's weird but my lesbian-ness helped me accept my body image . . . well, in some spaces. Locker rooms can make me feel like it's simultaneously not acceptable to be fat or to be gay.

For some participants who self-identified as a visible minority, intersections between race, ethnicity, gender, and sexuality influenced their conceptions of body image. Roxanne, a 27-year-old Black lesbian ciswoman, explained how "for me, my body image, my LGBTQ+ identity, and my blackness are themselves connected. I'm a black fat gay girl-my experiences and feelings about my body are going to reflect that." Ari, a 23-year-old Black queer ciswoman, described how:

Society sees Black women as more aggressive and less womanly than White women. Lesbians are immediately considered more masculine than straight girls. Fat people are seen as just lazy and gross. And here I am just trying to live my best life as all three, but I can't help but feel like I'm put on display in locker rooms. I just want to change into my sports bra and get a little bit of a sweat on and everyone just seems to stare.

Harmful stereotypes and blatant societal misconceptions seemed to greatly impact how fellow locker-room patrons viewed the participants' bodies, as well as how the participants viewed their own bodies.

Over time, a few participants were able to find the confidence to challenge their own insecurities, as well as the perceived reactions of other locker-room patrons. Sarah, a 45-year-old White lesbian ciswoman, now frequents her local gym and explained how "I feel more comfortable with my body than I did when I was younger. I no longer feel obligated to hide or be ashamed of it. I'm old-everyone can just deal with it." Some older and confident participants shifted the onus associated with bodily shame onto other locker-room patrons (and, by extension, society at large). These sentiments were also expressed by Kore, a 44-year-old Indigenous pansexual gender-fluid individual:

I have absolutely no fear of showing my body in locker rooms. I did as a young adult but now I have thankfully hit the age where I just don't care anymore. If people don't like it-if they don't like me, for whatever inexplicable reason-if they don't 
like the way I look, well then, they ought not to be looking at me. It's as plain as that.

\section{Sexual Transgression}

Locker rooms are organized along the gender binary to dissuade unwanted heterosexual advances and generate spaces of nonsexualized nudity. Individuals who do not adhere to heterosexuality in using locker rooms transgress the implicit heterosexual desire that maintains the binary division of these spaces. As Taylor, a 27-yearold White queer gender-fluid person, aptly explained,

I felt, especially as a teen, and continue to feel that my presence in locker rooms is a transgression. These spaces are sex segregated and the perceived reason is sexual: to keep people's attraction separated. As a queer person, I transgress against this system in varied ways, and it causes me discomfort and makes me feel unsafe.

The sexual transgression of locker rooms experienced by the participants was informed by the pervasive stereotyping of gay men as effeminate and lesbian women as masculine. Subsequently, two prevalent stereotypes emerged: (a) the predatory lesbian and (b) the effeminate and vulnerable gay man.

Predatory Lesbian. The participants who identified as sexual minority women were stigmatized as being predatory, like Jenna (a 27-year-old White queer ciswoman), who was "afraid of being perceived as an unwanted aggressor" within locker rooms. Across our survey, 217 self-identified sexual minority women communicated their experiences navigating and challenging this pervasive stereotype. Natasha, a 25-year-old White queer ciswoman, recalled how "throughout school I was very afraid of being considered predatory and this fear of being the 'predatory lesbian' has followed me into adulthood, even in contexts not related to exercise or change rooms." The "stereotype of the predatory lesbian" as titled by Blaire (a 23-year-old White lesbian ciswoman) can be fueled by homophobic locker-room talk that seems to be present across physical education, sport, and physical activity settings. For Emily, an 18-year-old White lesbian ciswoman,

The locker room isn't a good environment anywhere, sports, PE-it doesn't matter. Girls make jokes about lesbians, and there is always an implied predatory aspect to these stupid jokes. I never feel safe changing near those girls and that's a little ironic considering they'd apparently feel the same if they knew I was gay.

Although Emily was speaking to her relatively recent high school experiences, older participants also called upon their high school experiences to help explain their current feelings toward locker rooms and, by extension, physical activity. Like many participants, Joanne (a 23-year-old White queer ciswoman) tried to minimize the amount of nudity she displayed as well as observed while changing for physical education class. Joanne recalled how "in high school I was so worried about using locker rooms that I'd literally change in a shower so I could be alone. I think since then I've associated doing exercise with the annoyance of taking forbloody-ever getting changed." Although Joanne was, and to some degree still is, frustrated by her experiences changing in the shower cubicles, Ava (a 30-year-old mixed race bisexual ciswoman) calmly explained how "I always change in a stall. I do it to be respectful of the other women there. I'm not comfortable, but I'm not uncomfortable-I'm awkward, but that's just how it is/how it's always been." For Ava, changing in a stall was framed as a prerequisite for, instead of a hindrance to, sharing the locker room with other, assumedly straight, women. Alternatively, Hazel, a 28-year-old mixed race queer ciswoman and long-distance runner, changed separately from her teammates until they explicitly invited her to change with them:

I changed in the washroom because I didn't want to be seen as a creep, but in grade 12 all of the girls on the team confronted me and told me they didn't care that I was gay. They said that they didn't need me to go into the washroom to change and that they would prefer that I changed with them so as not to interrupt our conversation.

For some participants, previous locker-room experiences engaging with these stereotypes were formative to how they currently view and engage with locker rooms. Childhood experiences of discrimination while changing for physical education class were found to be especially poignant for the participants. Karen, a 27-year-old East Asian bisexual ciswoman, recalled how "my high school classmates forced me to change separately because they were worried, I might sexually assault them since I was bisexual. I still feel like a trespasser in locker rooms and it's been like ten fucking years." For Cassady (a 25-year-old White queer ciswoman), her previous locker-room experiences have culminated in her avoidance of physical activity into adulthood:

When I came out, I was bullied mercilessly in gym class. The changing room was the worst. No adulthood supervision-so kids are free to be as nasty as they want. Locking me in the stall because I was a "pervy dyke," so I had to crawl on the floor to get out for class. Putting my gym strip in the toilet just because. For many kids, myself included, gym class is their only time to participate in physical activity. I'm an adult now and I actively refuse to subject myself to gym settings because I don't want to use a locker room ever again.

Derogatory stereotypes are used throughout physical education settings to intimidate and tyrannize sexual minority women. Interconnected to and conflated with the stereotype of the predatory lesbian is the stereotype of the promiscuous bisexual woman. Julia, a 21-year-old White bisexual ciswoman and Quidditch player, explained how "I've definitely had girls who were very uncomfortable in change rooms with me-thinking I would be attracted to them if I saw them half naked. I'm bisexual but that doesn't mean I'm attracted to every person I see!" Similarly, Reese, a 23-year-old Black bisexual ciswoman expressed that "when I came out as bi, I was simultaneously viewed as threatening and as competition-girls didn't know how to react in the locker room, so I think they just defaulted to being jerks."

In particular, masculine-presenting female-identified participants were subjected to additional scrutiny within locker rooms. Leighton, a 36-year-old White lesbian ciswoman, reported that

Locker rooms can be very intimidating to anyone who doesn't conform to stereotypically feminine dress or looks. I am almost 6 feet tall, have a large frame, short hair, and am most comfortable in men's sizes/styles of clothing. I frequently get looks when entering women's locker rooms or washrooms, so I am reluctant to join gyms or pools. 
Most masculine-presenting female-identified participants were worried about being told that they are in the wrong locker room by a patron. For example, Evelyn, 25-year-old Indigenous queer ciswoman described how "I've been told that I'm in the wrong change room on multiple occasions, particularly at pools, because I present as quite masculine despite being female." Addison, a 50-year-old butch-presenting White queer ciswoman, explained how "gender policing in locker rooms still happens. I've had security called on me and been escorted out several times in recent years." Many masculine-presenting or androgynous female-identified participants used similar coping mechanisms within locker rooms to preemptively avoid being misgendered. Maeve, a 33-year-old White androgynous queer ciswoman and current weightlifter, described how

I am always nervous in public washrooms/change rooms/ locker rooms, etc. What I do to compensate is keep my head down, making sure not to look at anyone's body. I also try to speak to someone, small talk with strangers or with a friend, and I use the highest register of my voice to indicate that I'm both female and in the right change/washroom. I find it really stressful, and have had a few (not many, but they've stuck with me) interactions where people have tried to physically remove me from the women's change room or have made comments or otherwise indicated their confusion/ discomfort with my presence.

Anaya, a 29-year-old East Asian butch-presenting lesbian ciswoman, described how "when I must deal with changing rooms I try and go in with an obviously feminine-presenting woman friend, so she provides 'cover' for my existence." Some participants, like Valerie, a 27-year-old White soft butch lesbian ciswoman and current recreational softball player, were able to find locker rooms later in life where their masculine gender expression did not position them as a target for judgmental strangers:

Post high school, I was able to express my masculine side more, but this made me feel that people were staring when I was in the locker rooms. I have always tried to conceal that I'm a lesbian in sports situations, so my teammates aren't afraid I'm attracted to them, but recently I've been very happy playing in an all-gay softball league — so that's been a big weight off. Changing isn't a big deal anymore.

Thankfully, some sporting contexts are more inclusive of sexual minority female athletes and can operate as a refuge for sexual minority women. Everleigh, an 18-year-old White bisexual ciswoman and intercollegiate rugby player, explained how "strangers may think it's weird to change near me but that's pretty much it. All of my teammates are more than okay with it. It's not a big deal." For some athletes, their team and, subsequently, their team locker room were incredibly inclusive. Fiona, a 23-year-old White queer ciswoman and intercollegiate hockey player, explained how "on my team, it's flipped - if anything you might get singled out if you're not accepting of lesbians on the team and in the changing room." Although some participants spoke to inclusive and welcoming team locker-room experiences, it is important to note that this was not always the case. For example, Kinsley, a 24-year-old Caribbean queer ciswoman and recently retired basketball player, shared,

I was quite hesitant as a teen to come out because I feared being ostracized in the changeroom before/after practice. I would try to not make others uncomfortable by changing either alone in a stall or much earlier before practice to ensure no rumors would be spread about me being creepy in the changeroom. I still have fears associated with using public locker rooms, but despite my fears I have continued to enjoy many different types of physical activity.

Although the participants may struggle with varied feelings and experiences of embodiment within locker rooms, some participants, like Kinsley, persevere to engage in physical activity. Ruby, an 18-year-old White lesbian ciswoman, also expressed how "same-sex locker rooms used to stress me out. I was afraid girls would think I was looking at them if they found out I was gay. I withdrew from sports for many reasons, my sexuality being one of them." However, Ruby was recently able to reengage with her favorite sport, soccer, through an LGBTQ+ community league. Like Ruby, some participants actively sought out LGBTQ+ inclusive physical activity spaces. Sadie, a 24-year-old White queer ciswoman, described how "I feel more comfortable in spaces that are inclusive. I keep an eye out for gyms that have rainbow flags and gender-neutral locker rooms-I attend an inclusive yoga studio and my Muay Thai studio has private change rooms."

Although the majority of the participants described negative feelings of embodiment when using locker rooms, a few sexual minority women did not. For example, Joyce, a 49-year-old White pansexual ciswoman, explained that 'I've never had an issue with locker rooms. I chat with the ladies, in that polite 'passing through' way, and we all dress and shower and keep to ourselves." A few participants felt confident in locker rooms, like Noah, a 27-year-old White lesbian ciswoman who enjoys weight lifting and cardio sessions at her local gym. Noah asserted how "I feel great in locker rooms. I mean, it's just a place to change-it's only awkward if you make it awkward."

Effeminate and Vulnerable Gay Man. For some participants who identified as sexual minority men, locker rooms were viewed, in the words of Matthew (a 30-year-old White pansexual cisman), as an "absolute hell-a place to be bullied or harassed." Across 153 participants who self-identified as sexual minority men, a fear of or experiences of homophobia within locker rooms were conveyed. Bradley, a 23-year-old White gay cisman, disclosed how "the locker room has been the space where I am the most shamed, harmed, and oppressed-always verbally and sometimes even physically threatened." For some, like Devin (a 20-year-old White gay cisman), "locker rooms are definitely my most feared part of any type of physical activity." The participants' previous experiences with discrimination in locker rooms commonly took place during adolescence in school or sport locker rooms. Grayson, a 27-year-old mixed race queer cisman, described,

Locker rooms are terrible, but locker rooms as a kid are the worst. Especially in school, I was pegged as gay from the get-go and needlessly tormented. I distinctly remember having to change in a stall because some asshole classmates would always try to pull my boxers down or they would flash me.

Many participants described being verbally discriminated against in locker rooms. For example, Calvin, an 18-year-old White gay cisman, reported how "I've been called a lot of things-sissy, pussy, homo, gaylord, whatever. Teens aren't creative and they're cowardly. Locker rooms, fields, hallways-just wherever or whenever teachers aren't there, that's when the harassment picks up." The lack of supervision within locker rooms was cited by a handful of participants as a contributing factor to 
their previous experiences with discrimination. Joel, a 25-year-old Latinx bisexual cisman, explained how "locker rooms are like a perfect storm for bullying in school. Testosterone, teenage insecurities, hormones, and no supervision? Of course, that's where antigay slurs go flying. Of course, that's where I was harassed." For many, heterosexist locker-room talk reinforced the idea that sexual minority men are not welcome. Jared, a 26-year-old White gay cisman, expressed these sentiments of dread:

I am always worried about being perceived as gay/outed in locker rooms. I fear any eye-contact, or that a wrong look could lead to physical violence. I also overhear homophobic language, which reinforces locker rooms as a "straight" place that I must pass in, out of fear of violence.

For many participants, the fear for personal safety was exacerbated by frequently overhearing heterosexist lockerroom talk. As Bryce, a 26-year-old queer White cisman, states, "I hate locker rooms. The gym bro talk puts me on high alert, so I don't give off the vibe that I'm checking people out. I don't want to suffer some sort of retaliation from someone getting the wrong idea." Commonplace heterosexist locker room or "gym bro" talk worked to position the participants who self-identified as sexual minority men as outsiders. For example, Caleb, a 20-year-old mixed-race Middle Eastern and White gay cisman, explained how "I've always felt quite lonely in locker rooms. They're such masculine spaces and I couldn't engage in most of the conversations because they revolved around sex. It made me feel uneasy, isolated, and like I just couldn't relate." The participants often felt that locker-room talk was a method used to perpetuate the ideal that men's locker rooms are, in the words of Wesley (a 22-yearold White queer cisman), "extremely heteronormative and aggressively masculine spaces." Carson, a 24-year-old White queer cisman, explained:

I do not feel comfortable accessing facilities like locker rooms in gyms. I perceive these spaces as hyper masculine and heterosexual, and don't see myself fitting it. I also fear a "what if" scenario that an innocent glance or look to another man could be perceived negatively and put me at risk of harm. I think rationally, I know that this and many of my other fears are unfounded, but they still become an easy excuse not to engage in exercise beyond queer spaces.

Within heteronormative spaces like locker rooms, the participants were often afraid of being caught in the act of looking. Phillip, a 26year-old Hispanic queer cisman, described how "I always look down in locker rooms, fearing that someone might think I'm watching them." Other participants, like William (a 31-year-old White gay cisman and crossfit enthusiast), welcomed the prospect of being subject to the male gaze: "sometimes I catch the odd gawker now and then, but it's of no real importance to me. It's a bit flattering to be honest." In short, the dynamics involved in the male gaze that permeates men's locker rooms were experienced in a variety of ways.

Hyper or toxic masculinity characterized men's locker rooms for many participants and was often seen as a way to legitimize heterosexual men's dominant or superior social standing and justify the marginalization of others. A common stereotype used to profile and subordinate participants was that sexual minority men are effeminate and therefore weaker than straight men. Dominique, an 18-year-old South Asian gay cisman, described,
I am stereotyped as weak and feminine. I remember waiting every day for one cubicle inside our men's locker room to get into my gym clothes. Inside the change room, my classmates were constantly judging and picking on me-claiming I was checking them out. Every day I wanted to scream "I am gay, but I have standards!" But I couldn't, I would just wait for all of them to leave or I bow my head to pass by. They'd call me weak, call me a girl, ask where my sports bra is-I am gay, but I am not weak. I don't want that kind of treatment just because of some stereotype they have in mind. I feel disrespected every time people pull this shit, but I can't do anything. I am just by myself when they have an army.

This fear of being perceived as feminine and "less than" was also something experienced by more masculine-presenting sexual minority men. Ryan, a 28-year-old White queer cisman and cyclist, explained,

I've always been uneasy in locker rooms - the intensely gendered nature of it, it's a very masculine, heteronormative, male space, so I'm pretty uncomfortable. I'm a masculine guy but I feel like if I were to exercise with another queer man and to "act all gay" in the locker room, it would be frowned upon. It's like I'm worried to be seen as gay-to be seen as feminine-in locker rooms because it'll paint a target on my back.

Sexual minority men can also reiterate a hierarchy of masculinity dictated by rigid standards of attractiveness. Kane, a 20-year-old White gay cisman who has a visual impairment, expressed,

I can't stand locker rooms. The feeling of vulnerability in a room that literally smells of masculinity is overwhelming. I try to go to the gym when varsity teams aren't practicing and when it's as quiet as possible to avoid crowded locker rooms. I don't want people to think I'm staring when I literally can't. Most of the time, I don't really want to go to the gym, but at the same time, gay men have ridiculous body image standards, so I feel like I have to, to stay fit.

When using men's locker rooms, several participants used passing as a vigilance tactic to facilitate their personal safety and were subsequently able to use locker rooms with little incidence. Derrick, a 36-year-old White gay cisman, claimed that "I've never felt uncomfortable in locker rooms because I have been able to hide my sexuality easily and no one has ever suspected that I was gay." Richard (a 27-year-old White bisexual cisman) specifically modified his dress to be read as straight: "sometimes at the gym I worry that I might get assaulted in the locker room for wearing anything that could be deemed gay. So, I put on my 'bro costume' to work out. It's a small price to pay." Some participants who passed as heterosexual within locker rooms were still subject to indirect homophobia and, in some cases, bearing witness to the discrimination of others. For example, Terrence, a 49-year-old White gay cis man, remembered,

I reached puberty before the rest of the boys in my small town and was spared the bullying other gayboys had because of my body hair, facial hair, and developed genitals. I saw terrible bullying of others, though, including an attack they called "blackballing," in which the victims' genitals were forcibly bound with hockey tape. But I never intervened and kept my head down. 
Not all participants were able to or believed that they were able to pass as heterosexual within locker rooms. Some, like Sylas, a 20-year-old White gay cisman and intercollegiate cross-country runner, instead went to great distances to avoid using the locker room while still accessing fitness facilities. Sylas expressed how "I'm terrified of locker rooms. I usually change at a friend's flat near the gym, even when it's winter and $-10^{\circ} \mathrm{C}$ and I' $\mathrm{m}$ in shorts, rather than use the locker room."

Although some participants had lasting negative connotations associated with locker rooms, others found that their fears were assuaged over time. For example, Randall (a 52-year-old White gay cisman) explained how "locker rooms were terrifying to me as a student in school because of bullying and homophobia. But now, they're pretty utilitarian. Everyone minds their business at my gym, making it very inclusive." Locker rooms in fitness facilities were often viewed as relatively safer than physical education locker rooms by the participants. Lyle, a 47-year-old White queer cisman, thoroughly explained,

I avoided school locker rooms. I kept to myself in my sport's locker room settings. At university, I found the relative anonymity freeing in locker rooms. Today I work out at [name of gym] and while I've had unpleasant experiences and I still hear gendered and/or homophobic and/or misogynist talk that makes me uncomfortable-I refuse to let that make those spaces unavailable to me.

The increased anonymity and maturity of fellow locker-room patrons helped some participants feel more comfortable later in life. Some participants attributed their increased comfortability within locker rooms to elevated levels of self-confidence. Sean, a 30-yearold White gay cisman and kick boxer, clarified how "as a queer teen, locker rooms are pretty shitty with testosterone proving ground full of idiocy. As an adult, it's a pretty neutral place. But much of that has to do with self-confidence." Other participants sought alternative or more inclusive fitness facilities, like Doug (a 29-year-old White gay cisman): "I now only workout in the gay village. The locker rooms are always full of gay men, so I haven't had any issues using them at all."

\section{Gender Transgression}

For transgender participants, locker rooms were viewed as a significant barrier to participation in physical activity. Kyle, a 33-year-old White queer transman, expressed how "locker rooms are often the main thing that will stop me from going to a gym, event, facility, etc." In this study, 200 self-identified transgender participants expressed how the binary gender organization of locker rooms inextricably complicated their locker-room experiences. Salem, a 22-year-old White queer agender person, iterated,

Locker rooms and bathrooms are explicitly organized by the gender binary. It's like "here is the space for women," "here is the space for men," and occasionally it's like "here is the space for people with mobility impairments and families ... and gender-neutral people" . . . we're all afterthoughts.

For the transgender participants seeking gender-affirming treatments and surgeries, locker rooms were established as particularly problematic premedical services. The participants, like Sawyer (a 27-year-old White bisexual transman), at the beginning of their social and/or medical transition were often frustrated and overwhelmed by choosing which locker room to use. Sawyer explained how “recently I started transitioning and I just don't want to have to deal with deciding which locker room to go intoso I don't go to the gym anymore." In addition, there is a sense of peril associated with making the "wrong" decision as expressed by Brook, a 29-year-old Hispanic queer transwoman: "transitioning is scary. I'm not sure when I should make the locker room switch, and it feels dangerous to do it too soon or too late." However, for genderqueer and nonbinary participants (i.e., people who reject the gender binary), locker rooms persistently presented two choices that did not represent them, as described by Riley, a 28-year-old White bisexual nonbinary person:

Society is largely built to adhere to the binary, so it's hard finding spaces that are accepting to those outside it. Which locker room do I use? I hesitate before choosing the women's locker room because I don't feel I belong there, but I belong even less in the men's locker room.

These feelings of not belonging or being forced to adhere to the gender binary they had rejected led some nonbinary participants to garner a strong dislike of locker rooms. For example, Celes, a 27-year-old Hispanic pansexual nonbinary person, asserted their strong sentiments toward locker rooms: "I hate them so much, because I'm nonbinary and I absolutely detest being gendered female or male." Similarly, Ainslie, a 24-year-old White queer agender person, elaborated on how either option is ultimately undesirable:

All of my experiences in locker rooms have been extremely triggering for my gender and body dysphoria. I struggle to decide which room to go into (male/female), I face violence and harassment in whichever room I go into, and struggle to find ways to change and dress without being stared at or harassed by others.

Ainslie, like many transgender participants, conveyed how they often feel like their personal safety was at risk when using gendered facilities. Hadley, a 24-year-old White pansexual agender person, also explained how "I feel extremely uncomfortable and unsafe because I am misgendered, gawked at, and face violence if I attempt to use a washroom, change room, or any other gendered space that doesn't fit my gender assigned at birth." Similarly, Vance, a 25-year-old White heterosexual transman with a slight mobility impairment, described how "locker rooms are incredibly uncomfortable, dysphoria-inducing, unsafe, actively hostile, and dangerous as a transman. They're often piss poorly designed or sometimes nonexistent for someone with a physical disability. Either way I'm screwed." Some participants, like Rylan, a 22-yearold White bisexual transman, viewed locker rooms as the most exclusionary out of all gendered facilities:

Locker rooms are the worst, they are even worse than public bathrooms, because not only do I have to pick a gendered room, I also feel more pressure to use the one associated with my assigned gender because (1) there are usually little to no stalls/privacy and (2) I have to change clothes in front of others. They make me nervous because I am exposing things that are normally hidden, like my unshaven legs and my choice in undergarments.

Some participants who directly experienced discrimination within locker rooms or who did not feel like locker rooms supported their gender identity, opted to avoid locker rooms, which sometimes led to avoiding fitness facilities and physical activity 
altogether. Samantha, a 36-year-old White bisexual transwoman, explained how "I don't use any gendered facilities because I don't feel safe. I don't work out because I refuse to step foot into a locker room." Similarly, Parker, a 20-year-old White asexual nonbinary person, responded, "I don't go to gyms now because I don't feel safe in either locker room." For the majority of the participants who identified as transgender, locker rooms were presented as a significant barrier to physical activity participation.

The transmen (female-to-male transgender individuals) in this study disclosed that, when using the men's locker room, they were often concerned about being sexually assaulted. Flynn, a 21-yearold White pansexual transman, communicated that "even though I have had top surgery, I would not be comfortable changing in a men's locker room because I do not have visibly male genitalia. I worry about being sexually assaulted, being in such a vulnerable position." Male locker rooms were regarded by some participants as spaces deeply rooted in conceptions of toxic masculinity that promote the objectification of women as well as perpetuate rape culture. Hollis, a 23-year-old White bisexual transman, clarified how 'I don't have to go into the men's locker room to know that it's bursting with toxic masculinity and locker room talk that's misogynistic, heterosexist, and transphobic as hell." Subsequently, some participants who were assigned female at birth felt like their personal safety was jeopardized when they used men's locker rooms. For example, Daniel, a 24-year-old Indigenous queer transman, explained how "these days I just don't use locker rooms at all, I fear being outed as trans and beaten or sexually assaulted as a result. I also have to be extra careful because I have yet to get bottom surgery." These concerns were echoed by Logan, a 22-year-old White queer transman, who described how "being in locker rooms is always scary. I am always afraid someone will realize I am trans and try to hurt me." Despite their safety concerns, many participants who self-identified as transmen felt compelled to start using male locker rooms when they initially began presenting as more masculine because they no longer felt like they belonged in the women's locker rooms. Wyatt, a 27-year-old White asexual transman, explained,

Locker rooms have become a large issue as I have recently begun HRT [hormone replacement therapy] but still do not entirely "pass." Men's locker rooms are currently unsafe and unwelcoming. However, I'm on the cusp of being found inappropriate in a women's locker room and therefore have a difficult time finding a safe space to prepare.

Although occupying the men's locker room was consistently viewed with trepidation by the participants, locker rooms with limited options for privacy were commonly regarded as the most terrifying. "Locker rooms suck when you're trans, but locker rooms with only a handful of bathroom stalls are the absolute worst. You're forced expose yourself," stated Cohen (a 23-year-old Middle Eastern bisexual transman). In particular, men's locker rooms with communal shower areas were viewed as the most difficult to navigate, as communicated by Evan, a 37-year-old White bisexual transman:

I have scarring on my body, which is readily apparent, but not widely known as the result of a gender affirming surgery. Depending on the arrangement of the space, especially levels of privacy, I get stares, questions, and occasionally masculineinfused hostility. The open concept showers that are still so prevalent in men's change rooms are heart stopping and anxiety provoking (and not just trans folks, but for cis guys too).
The participants who identified as transwomen (male-to-female transgender individuals) also experienced discomfort when using the women's locker room, as exemplified by Kerry, a 36-year-old White queer transwoman: "I've never felt comfortable in locker rooms. I feel even less comfortable as a transwoman with a penis." The participants felt unwelcome in the women's locker room, and these feelings were often corroborated by experiences of being asked if they were in the right locker room or being asked to leave the premises. For example, Sharon, a 27-year-old South East Asian bisexual transwoman, explained how "locker rooms are generally difficult to navigate, I am asked at least once a week whether I am in the right change room." In addition, Brianna, a 28-year-old White queer transwoman, expressed how "change rooms are incredibly humiliating-people have gone to the staff who have then approached me and asked me to leave." Some participants, in the words of Rachel (an 18-year-old White pansexual transwoman), believe that this maltreatment in women's locker rooms stems from the myth "that transgender women are actually just creeps trying to exploit the 'system' to ogle other women." The participants recalled how the common misbelief that transgender people, specifically transwomen, are a threat to ciswomen was often used to justify discrimination. Rayna, a 28-year-old Latinx demisexual transwoman, recollected how 'I've been banned from using the women's locker room before. Obviously, I don't go to that gym anymore. They claimed that the other women wouldn't feel safe with me there and treated me as if I was an intruder." However, some transwomen, like transmen, also viewed the men's locker room as a space where their personal safety would be put at risk. Malaya, a 31-year-old Middle Eastern pansexual transwoman, communicated how "in the men's locker room, I'm a target. In the women's locker room, I'm a threat. Either way I'm damned if I do, so I just avoid them altogether." Within men's locker rooms, transwomen are potentially subject to transphobic violence and assault, and in women's locker rooms, transwomen are viewed as a threat to cisgender female safety and are persecuted accordingly. Charlotte, a 21-year-old White bisexual transwoman, explained how "ever since I transitioned, I have never stepped in a men's locker room out of fear." Some transwomen feared being sexually assaulted in men's locker rooms. Victoria, a 25-year-old White queer transwoman, elaborated on her experiences using any sort of gendered facilities:

Being a transwoman places me in outright dangerous situations in regard to locker rooms, bathrooms - every single time I use those facilities. Being read queer draws attention from cishet men - they become violent or threatening because of an assumed sexual predation. As if my presence as a queer (ostensibly male) person directly threatens their straight male identities. I am at a far greater risk of sexual assault here than almost anywhere else. When trying to use facilities I identify with, as a "nonpassing" transwoman, I am then placed in more danger. In addition to being seen or read as a sexual threat I am also viewed, among female-bodied people, as a physical threat.

Victoria, like many transwomen, is effectively stonewalled from using locker rooms (in addition to other gendered facilities).

To use women's locker rooms without incident, some participants developed specific strategies over time. Audrey, a 41-yearold White queer transwoman, explained how she navigates locker rooms:

Two words: careful planning. Workout wear is all pretested at home to make sure nothing is going to be visible that shouldn't 
be. I wear skirts over workout gear on the way in, and then can easily change without exposure by putting the skirt on afterward and shucking shorts/leggings from under that cover. I used to change tops in bathroom stalls as I stuffed my sports bra with silicone falsies held in with tape.

A few participants who were confident in their ability to pass as a gender associated with a specific locker room felt less anxious assessing those gendered spaces. For instance, Anthony, a 32-yearold White heterosexual transman, acknowledged that "because I comfortably pass as a man now, I feel comfortable using the men's locker room." Similarly, Rhea, a 29-year-old East Asian bisexual transwoman, explained how "I am seriously lucky because I've always passed pretty easily as a woman, and now that I'm done with my surgeries, I feel extra comfortable being naked and changing in the women's locker room."

Given that locker rooms are critical access points to most physical activities, many participants felt forced to jeopardize their safety to be healthy. Maya, a 29-year-old Middle Eastern queer transwoman, explained how she ironically needs to put her wellbeing at risk to improve her physical health: "I get anxiety when approaching and in locker rooms. I have to put on a brave face because I know my physical health is just as important as any cis person who doesn't have to think about locker rooms." Similarly, Kai, a 23-year-old White queer transman, mused about how "it's like you have to jump through all of these hoops-forget motivation and actually getting to the gym, then there's locker rooms and transphobic gym bunnies - all to literally jump through hoops for an hour."

It is important to understand that these narratives of transgressing the gender binary are not limited to locker rooms. As Laurel, a 24-year-old White queer nonbinary person, notes, "bathrooms, locker rooms, sports teams, gendered clothing, gendered languagethe list goes on and on, society revolves around the binary." The gender binary is deeply entrenched within society and perpetuated through various institutions; subsequently, shifts toward transgender inclusion take time, advocacy, and work. As noted by Charlie, a 22-year-old Middle Eastern queer nonbinary individual, "trans spaces are precious and needed. I'm one of the few lucky ones because my university has a gender-neutral changing room. Students had to fight for it. It's small-but it's better than nothing." Tegan, an 18-year-old White demisexual agender person, like our other transgender participants, was intimately aware of the real-life implications associated with not being cisgender: "this is not limited to change rooms-Gender expression as 'other' or 'queer' can lead to anything from dirty looks to extreme violence, all of which I have experienced firsthand."

\section{Discussion}

The purpose of this study was to expand our understanding of complex LGBTQ+ locker-room experiences. The two research questions guiding this study were (a) What are the experiences of self-identifying LGBTQ+ adults in locker-room spaces? and (b) How do these experiences influence overall physical activity experiences?

In line with previous literature, our findings demonstrate that locker rooms pose a significant barrier toward LGBTQ+ participation in physical activity (Devís-Devís et al., 2018; Herrick \& Duncan, 2018a; Jones et al., 2017b; Sykes, 2011). The participants' experiences within locker rooms were greatly impacted by their experiences of embodiment informed by body image, sexuality, and gender. Within Western society, "healthy" or "fit" bodies are commonly used as a measure of social success and desirability (Greenhalgh, 2012). As a result, some participants' feelings of selfconsciousness stemmed from societal fatphobia and standardized conventions of attractiveness that were exacerbated by the nudity within locker-room settings. The participants who self-identified as fat shared the experiences of being subjected to heightened surveillance, judgment, and shame within locker rooms. For some participants, their body image was deeply interrelated with their sexuality, gender, and other aspects of their identity. A recent systematic review of LGBTQ+ experiences within physical activity found that sexual minority men and women were influenced by different ideal body images (Herrick \& Duncan, 2018b). The findings from this review indicate that sexual minority men were often motivated to exercise through a rigid body image ideal that emphasized being muscular and thin (Herrick \& Duncan, 2018b). Within this study, some participants who identified as sexual minority men reiterated the pervasive nature of this specific body ideal and how the pressure they felt to meet it was often exacerbated by the culture of body surveillance within locker rooms. Contrastingly, sexual minority women have been found to be more fat positive and seek to actively reject mainstream standards of beauty (Herrick \& Duncan, 2018b; Wykes, 2014). However, it should be noted that, within this study, some participants who identified as sexual minority women expressed feeling self-conscious about their bodies not meeting societal standards for presumably "healthy" or thin bodies when using locker rooms.

The sexual transgression of locker rooms experienced by the participants was heavily influenced by the widespread stereotyping of lesbian women as masculine and gay men as effeminate (Eng, 2008; Fusco, 1998; Kauer \& Krane, 2006). Derogatory stereotypes and widespread misconceptions were often used to justify discrimination within locker rooms. Bullying and harassment within sport and physical education based on sexual orientation is a longstanding phenomenon (e.g., Denison \& Kitchen, 2015; Gill, Morrow, Collins, Lucey, \& Schultz, 2006; Kosciw, Greytak, Giga, Villenas, \& Danischewski, 2016; Kosciw et al., 2018; Morrow \& Gill, 2003). Our findings illustrate how formative negative locker-room experiences in physical education or athletics can be for LGBTQ+ adults. For both sexual minority men and women, pernicious locker-room talk was found to reinforce the idea that LGBTQ+ persons are unwelcome. Subsequently, creating more inclusive climates in school and athletic locker rooms by debunking stereotypes and not tolerating heterosexist talk may help minimize negative experiences for current LGBTQ+ youth, which in turn, may foster an increased likelihood to access fitness facilities later in life. Although some LGBTQ+ inclusive workshops and informational kits exist for teachers and coaches (e.g., Egale Canada Human Rights Trust, 2019; Gay, Lesbian and Straight Education Network, 2016; LGBT SportSafe, 2019), attention should be directed toward training and empowering youth to speak up against LGBTQ+ prejudices in locker rooms.

Previous research has demonstrated how locker rooms cultivate a climate of exclusion that is primed to operate as an active site of transphobia (Cunningham et al., 2018; Fusco, 2012; Hargie, Mitchell, \& Somerville, 2017; Sykes, 2009, 2011). Hostility is often based upon the common misbelief that transgender people are a threat to cisgender livelihood (Cunningham \& Pickett, 2018; Eckes, 2017). Our findings illustrate how the binary organization of locker rooms inherently impedes upon transgender access and hinders physical activity participation. These findings align with recent studies that have also identified locker rooms as a significant 
barrier to transgender participation in sport and physical education (Devís-Devís et al., 2018; Hargie et al., 2017; Jones et al., 2017b). However, across previous physical activity research, the transgender experiences represented are typically limited to participants who self-identify as either transmen or transwomen (e.g., Caudwell, 2014; Devís-Devís et al., 2018; Elling-Machartzki, 2017; Hargie et al., 2017; Jones et al., 2017a; Klein, Krane, \& Paule-Koba, 2018). This study provides some initial insight into the variability of transgender locker-room experiences, with the inclusion of nonbinary, agender, genderqueer, gender-fluid, and two-spirited lived experiences. In light of recent reports calling for more trans-inclusive locker rooms across physical activity contexts (e.g., Cunningham et al., 2018; Greenspan, Whitcomb, \& Griffith, 2019), the findings of this study suggest that (a) increased privacy options be made available in all locker rooms, (b) gender-neutral locker room creation be prioritized and advocated for, and (c) the binary division of locker rooms be challenged.

We acknowledge that our results may be biased toward individuals who were specifically interested in a survey about physical activity, as the respondents self-selected to participate. Given that all open-ended questions were optional, the participants included in this study presumably wanted to convey their experiences with locker rooms. For the sake of anonymity, we were also unable to follow up with the participants and ask for clarification on their submitted responses.

\section{Conclusions}

Locker rooms are pivotal access points to physical activity settings; however, LGBTQ+ access is often complicated by varying experiences of discrimination. Prior to this research, the majority of studies have focused on traditionally smaller scale qualitative investigations into LGBTQ+ locker-room experiences (e.g., Fusco, 1998; Hargie et al., 2017; Sykes, 2009). Due to the unique methods ascribed to this study, our results represent an amalgamation of over 1,000 LGBTQ+ adult voices sharing their personal experiences with locker rooms. This research corroborates the previous findings in this field, as well as provides a level of undeniability to the widespread and nuanced concerns locker rooms pose to LGBTQ+ communities. Despite societal movement toward LGBTQ+ inclusion, locker rooms still represent an unsafe space for many LGBTQ+ adults. More research and work is always required to incite social change; however, it is our hope that this study will represent a turning point wherein researchers will be able to move past establishing that locker rooms are problematic for LGBTQ+ persons and instead dedicate resources to changing the culture and organization of locker rooms to be truly LGBTQ+ inclusive.

\section{Note}

1. The participants' various identities are presented without being separated by commas to illustrate the complex intersection of a multitude of identities. Although presented in a standardized order, we would like to acknowledge that there is no implicit hierarchy of significance to our participants' identities.

\section{Acknowledgment}

The authors would like to thank our research assistant, Alexandra Moisan, for all of her hard work throughout the coding process of this study.

\section{References}

Beemyn, B.G., Domingue, A., Pettitt, J., \& Smith, T. (2005). Suggested steps to make campuses more trans-inclusive. Journal of Gay \& Lesbian Issues in Education, 3(1), 89-94. doi:10.1300/ J367v03n01_09

Braun, V., Clarke, V., \& Weate, P. (2016). Using thematic analysis in sport and exercise research. In B. Smith \& A.C. Sparkes (Eds.), Routledge handbook of qualitative research in sport and exercise (pp. 213-227). Routledge Handbooks Online. doi:10.4324/9781315762012.ch15

Caudwell, J. (2014). [Transgender] young men: Gendered subjectivities and the physically active body. Sport, Education and Society, 19(4), 398-414. doi:10.1080/13573322.2012.672320

Clarke, V., \& Braun, V. (2013). Teaching thematic analysis: Overcoming challenges and developing strategies for effective learning. The Psychologist, 26(2), 120-123. Retrieved from http://eprints.uwe.ac.uk/21155

Cover, R. (2003). The naked subject: Nudity, context and sexualization in contemporary culture. Body \& Society, 9(3), 53-72. doi:10.1177/ 1357034 X030093004

Cunningham, G.B., Buzuvis, E., \& Mosier, C. (2018). Inclusive spaces and locker rooms for transgender athletes. Kinesiology Review, 7(4), 365374. doi:10.1123/kr.2017-0062

Cunningham, G.B., \& Pickett, A.C. (2018). Trans prejudice in sport: Differences from LGB prejudice, the influence of gender, and changes over time. Sex Roles, 78(3-4), 220-227. doi:10.1007/ s11199-017-0791-6

Davidson, M. (2007). Seeking refuge under the umbrella: Inclusion, exclusion, and organizing within the category transgender. Sexuality Research and Social Policy, 4(4), 60-80.

Denison, E., \& Kitchen, A. (2015). Out on the fields: The first international study on homophobia in sport. Nielsen, Bingham Cup Sydney 2014, Australian Sports Commission, Federation of Gay Games. Retrieved from www.outonthefields.com

Dermer, S., Smith, S., \& Barto, K. (2010). Identifying and correctly labeling sexual prejudice, discrimination, and oppression. Journal of Counseling \& Development, 88(3), 325-331. doi:10.1002/j.15566678.2010.tb00029.x

Devís-Devís, J., Pereira-García, S., López-Cañada, E., Pérez-Samaniego, V., \& Fuentes-Miguel, J. (2018). Looking back into trans persons' experiences in heteronormative secondary physical education contexts. Physical Education and Sport Pedagogy, 23(1), 103-116. doi:10.1080/17408989.2017.1341477

Eckes, S.E. (2017). The restroom and locker room wars: Where to pee or not to pee. Journal of LGBT Youth, 14(3), 247-265. doi:10.1080/ 19361653.2017.1324345

Egale Canada Human Rights Trust. (2019, September 27). You can play Canada. Retrieved from http://youcanplayproject.org/

Elling-Machartzki, A. (2017). Extraordinary body-self narratives: Sport and physical activity in the lives of transgender people. Leisure Studies, 36(2), 256-268. doi:10.1080/02614367.2015.1128474

Eng, H. (2008). Doing Sexuality in Sport. Journal of Homosexuality, 54(1-2), 103-123. doi:10.1080/00918360801951996

Fredriksen-Goldsen, K.I., Kim, H.-J., Bryan, A.E.B., Shiu, C., \& Emlet, C.A. (2017). The cascading effects of marginalization and pathways of resilience in attaining good health among LGBT older adults. The Gerontologist, 57(Suppl. 1), S72-S83. doi:10.1093/geront/gnw170

Fusco, C. (1998). Lesbians and locker rooms: The subjective experiences of lesbians in sport. In Genevieve Rail (Ed.), Sport and postmodern times (pp. 87-116). Albany: State University of New York Press.

Fusco, C. (2006a). Inscribing healthification: Governance, risk, surveillance and the subjects and spaces of fitness and health. Health \& Place, 12(1), 65-78. doi:10.1016/J.HEALTHPLACE.2004.10.003 
Fusco, C. (2006b). Spatializing the (im)proper subject. Journal of Sport \& Social Issues, 30(1), 5-28. doi:10.1177/0193723505278457

Fusco, C. (2012). Critical feminist/queer methodologies: Deconstructing (Hetero)normative inscriptions. In K. Young \& M. Atkinson (Eds.), Qualitative research on sport and physical culture (pp. 151166). Bingley, UK: Emerald Group Publishing Limited. doi:10. 1108/S1476-2854(2012)0000006010

Gay, Lesbian and Straight Education Network. (2016). GLSEN safe space kit: Be an ALLY to LGBTQ youth! Retrieved from https://www. glsen.org/activity/glsen-safe-space-kit-be-ally-lgbtq-youth

Gill, D.L., Morrow, R.G., Collins, K.E., Lucey, A.B., \& Schultz, A.M. (2006). Attitudes and sexual prejudice in sport and physical activity. Journal of Sport Management, 20(4), 554-564. doi:10.1123/jsm. 20.4.554

Gill, D.L., Morrow, R.G., Collins, K.E., Lucey, A.B., \& Schultz, A.M. (2010). Perceived climate in physical activity settings. Journal of Homosexuality, 57(7), 895-913. doi:10.1080/00918369.2010.493431

Greenhalgh, S. (2012). Weighty subjects: The biopolitics of the U.S. war on fat. American Ethnologist, 39(3), 471-487. doi:10.1111/j.15481425.2012.01375.x

Greenspan, S.B., Griffith, C., Hayes, C.R., \& Murtagh, E.F. (2019). LGBTQ + and ally youths' school athletics perspectives: A mixedmethod analysis. Journal of LGBT Youth, 16(4), 403-434. doi:10. 1080/19361653.2019.1595988

Greenspan, S.B., Whitcomb, S., \& Griffith, C. (2019). Promoting affirming school athletics for LGBTQ youth through professional development. Journal of Educational and Psychological Consultation, 29(1), 68-88. doi:10.1080/10474412.2018.1482217

Griffith, C., Akers, W., Dispenza, F., Luke, M., Farmer, L.B., Watson, J.C., ... Goodrich, K.M. (2017). Standards of care for research with participants who identify as LGBTQ+. Journal of LGBT Issues in Counseling, 11(4), 212-229. doi:10.1080/15538605.2017.1380549

Hargie, O.D., Mitchell, D.H., \& Somerville, I.J. (2017). "People have a knack of making you feel excluded if they catch on to your difference": Transgender experiences of exclusion in sport. International Review for the Sociology of Sport, 52(2), 223-239. doi:10.1177/ 1012690215583283

Hekma, G. (1998). As long as they don't make an issue of it . . . : Gay men and lesbians in organized sports in the Netherlands. Journal of Homosexuality, 35(1), 1-23. doi:10.1300/J082v35n01_01

Herrick, S.S.C., \& Duncan, L.R. (2018a). A qualitative exploration of LGBTQ+ and intersecting identities within physical activity contexts. Journal of Sport \& Exercise Psychology, 40(6), 325-335. doi:10. 1123/jsep.2018-0090

Herrick, S.S.C., \& Duncan, L.R. (2018b). A systematic scoping review of engagement in physical activity among LGBTQ+ adults. Journal of Physical Activity \& Health, 15(3), 226-232. doi:10.1123/jpah.20170292

Herrick, S.S.C., Rocchi, M.A., Sweet, S.N., \& Duncan, L.R. (2019, September). Exploring $L G B T Q+$ minority stressors within physical activity contexts from a self-determination theory perspective. Paper presented at the 33rd Annual Conference of European Health Psychology Society, Dubrovnik, Croatia.

Jackson, S. (2006). Interchanges: Gender, sexuality and heterosexuality: The complexity (and limits) of heteronormativity. Feminist Theory, 7(1), 105-121.

Jones, B.A., Arcelus, J., Bouman, W.P., \& Haycraft, E. (2017a). Barriers and facilitators of physical activity and sport participation among young transgender adults who are medically transitioning. International Journal of Transgenderism, 18(2), 227-238. doi:10.1080/ 15532739.2017.1293581
Jones, B.A., Arcelus, J., Bouman, W.P., \& Haycraft, E. (2017b). Sport and transgender people: A systematic review of the literature relating to sport participation and competitive sport policies. Sports Medicine, 47(4), 701-716. doi:10.1007/s40279-016-0621-y

Kauer, K.J., \& Krane, V. (2006). "Scary dykes" and "feminine queens": Stereotypes and female collegiate athletes. Women in Sport and Physical Activity Journal, 15(1), 42-55. doi:10.1123/wspaj.15.1.42

Klein, A., Krane, V., \& Paule-Koba, A.L. (2018). Bodily changes and performance effects in a transitioning transgender college athlete. Qualitative Research in Sport, Exercise and Health, 10(5), 555-569. doi:10.1080/2159676X.2018.1466721

Kosciw, J.G., Greytak, E.A., Giga, N.M., Villenas, C., \& Danischewski, D.J. (2016). The 2015 National School Climate Survey: The experiences of lesbian, gay, bisexual, transgender, and queer youth in Our Nation's Schools. New York, NY: Gay, Lesbian and Straight Education Network (GLSEN). Retrieved from https://eric.ed.gov/? id=ED574780

Kosciw, J.G., Greytak, E.A., Zongrone, A.D., Clark, C.M., \& Truong, N.L. (2018). The 2017 National School Climate Survey: The experiences of lesbian, gay, bisexual, transgender, and queer youth in our nation's schools. New York, NY: Gay, Lesbian and Straight Education Network (GLSEN).

Lewis, D.C., Flores, A.R., Haider-Markel, D.P., Miller, P.R., Tadlock, B.L., \& Taylor, J.K. (2017). Degrees of acceptance: Variation in public attitudes toward segments of the LGBT community. Political Research Quarterly, 70(4), 861-875. doi:10.1177/1065912917717352

LGBT SportSafe. (2019, August 6). LGBT SportSafe Inclusion Program. Retrieved from https://lgbtsportsafe.com/

Magrath, R., Anderson, E., \& Roberts, S. (2015). On the door-step of equality: Attitudes toward gay athletes among academy-level footballers. International Review for the Sociology of Sport, 50(7), 804-821. doi:10.1177/1012690213495747

Mann, M., \& Krane, V. (2018). Inclusion and normalization of queer identities in Women's College Sport. Women in Sport and Physical Activity Journal, 26(2), 76-88. doi:10.1123/wspaj.2017-0033

Mertens, D.M. (2007). Transformative paradigm: Mixed methods and social justice. Journal of Mixed Methods Research, 1(3), 212-225. doi:10.1177/1558689807302811

Meyer, I., \& Wilson, P. (2009). Sampling lesbian, gay, and bisexual populations. Journal of Counseling Psychology, 56(1), 23. Retrieved from http://psycnet.apa.org/record/2009-00624-011

Morrow, R.G., \& Gill, D.L. (2003). Perceptions of homophobia and heterosexism in physical education. Research Quarterly for Exercise and Sport, 74(2), 205-214. doi:10.1080/02701367.2003. 10609082

Pérez-Samaniego, V., Fuentes-Miguel, J., Pereira-García, S., López-Cañada, E., \& Devís-Devís, J. (2019). Experiences of trans persons in physical activity and sport: A qualitative meta-synthesis. Sport Management Review, 22(4), 439-451. doi:10.1016/J.SMR.2018.08.002

Scotland, J. (2012). Exploring the philosophical underpinnings of research: Relating ontology and epistemology to the methodology and methods of the scientific, interpretive, and critical research paradigms. English Language Teaching, 5(9), 9-16. doi:10.5539/ elt.v5n9p9

Short, D. (2007). The informal regulation of gender: Fear and loathing in the locker room. Journal of Gender Studies, 16(2), 183-186. doi:10. 1080/09589230701324751

Smith, B., \& Caddick, N. (2012). Qualitative methods in sport: A concise overview for guiding social scientific sport research. Asia Pacific Journal of Sport and Social Science, 1(1), 60-73. doi:10.1080/ 21640599.2012.701373 
Smith, B., \& McGannon, K.R. (2018). Developing rigor in qualitative research: Problems and opportunities within sport and exercise psychology. International Review of Sport and Exercise Psychology, 11(1), 101-121. doi:10.1080/1750984X.2017.1317357

Smith, B., \& Sparkes, A.C. (2005). Analyzing talk in qualitative inquiry: Exploring possibilities, problems, and tensions. Quest, 57(2), 213242. doi:10.1080/00336297.2005.10491854

Subhrajit, C. (2014). Problems faced by LGBT people in the mainstream society: Some recommendations. International Journal of Interdisciplinary and Multidisciplinary Studies, 1(5), 317-331.
Sykes, H. (2009). The qBody project: From lesbians in physical education to queer bodies in/out of school. Journal of Lesbian Studies, 13(3), 238 254. Retrieved from http://search.proquest.com/docview/235890104? accountid $=12339$

Sykes, H. (2011). Queer bodies: Sexualities, genders, and fatness in physical education. New York, NY: Peter Lang Publishing.

Wykes, J. (2014). Introduction: Why queering fat embodiment? In C. Pause, J. Wykes, \& S. Murray (Eds.), Queering fat embodiment (1st ed., pp. 1-13). New York, NY: Routledge. 